\title{
The Origin of the Peculiarity of Contemporary Chinese Arts and Crafts
}

\author{
Zhiqiang Lin \\ Xiamen Academy of Arts and Design \\ Fuzhou University \\ Xiamen, China
}

\begin{abstract}
Contemporary Chinese arts and crafts is no longer a concept of decorative art, folk craft and so on in traditional sense. It is more like a kind of design approach peculiar to contemporary China, which is called "creating". This kind of peculiar design approach since ancient China is different from modern design appearing after industrial revolution. This is a kind of genetic connection coming down in one continuous line. Due to this kind of relation, it owns peculiarity which is different from modern design.
\end{abstract}

Keywords—arts and crafts; peculiarity; modernization

\section{INTRODUCTION}

Arts and crafts is an important constitutional part of people's economic life and artistic life, is reflection of our living environment and human's cognition, and is a kind of phenomenon formed on the basis of social and economic development. It has its own special status and law characteristics.

\section{Discussion On PECULIARITy OF ARTS AND CRAFTS}

In his early years, Mr. Tian Zibing makes a lot of investigations on "arts and crafts" and points out: "Emphasizing on thinking of design is required by creation method change of modern arts and crafts." From discussion on "arts and crafts" in 1980s, we can see Mr. Zhang Daoyi's discussion on how to deal with relationship of modern industrial design, traditional arts and crafts, and folk art after visiting Japan. In his The Path to Decoration, Mr. Li Yanzu rediscovers craft and points out the concept from arts and crafts to craft culture. In contemporary era, Mr. Hang Jian thinks: "'arts and crafts' and 'art design' are not totally separated, and they are two processes of Chinese design needed to be re-recognized". A great batch of gentlemen of design art education also discuss a lot about the concept of "arts and crafts". Today, we have a more accurate recognition of arts and crafts and set up arts and crafts as an individual class of art at the same time. Undoubtedly, these are sublimation of our traditional understanding of design creation concept, thus making us find out our own path to design with our own tradition in post-industrial social development in modern times.

Research and Practice of Art Design Innovation Talent Cultivation Mode under Grand Design Vision, Project Number: 521002. Phased objective of Fujian province's college teaching reform and research special project in 2014; Phased objective of "Major project of Fuzhou University higher education teaching reform project".
Arts and crafts is a peculiar design form of China. It has modern design concept and peculiar design features of China. China's arts and crafts has a long history and achievements with enormous varieties. In 5000 years ago, outstanding bronze ware of arts and crafts has appeared in China, like lacquer ware in the Spring and Autumn, stone relief and silk fabrics of Han dynasty, Song porcelain, Ming furniture and so on. Various ceramic wares, glass wares, bamboo and rattan woven goods, decoration paintings, packaging of goods etc. in modern times all belong to the category of arts and crafts. No matter which category it belongs to, categories of arts and crafts have common features, like they all own social function and appear to satisfy people's need. It has practical features in life and spiritual need in life.

Peculiarity of arts and crafts lies in using its own artistic image to arouse people's inspiration of beauty, enthusiasm in work, motivate their thinking and emotion and improve their life quality. Beautifying ordinary products with artistic ingenuity can arouse people's passion in life and make people feel the existence of "object". Products created by "arts and crafts" change people's life silently, which is a silent transforming process. This kind of process is closely related to realistic life and Chinese traditional "creation" concept. It has its own peculiarity.

\section{MANIFESTATION PATTERn Of PECULIARITY IN CHINESE ARTS AND CRAFTS}

\section{A. Contemporaneity}

Arts and crafts product is not only a necessity in life, it reaches requirements of artwork to some degree. It has design and production procedure and process needed by modern "design" and uses various materials, crafts and creative thoughts to make it a material existence. Therefore, arts and crafts needs to manifest its era characteristics and use arts and crafts products' material and craft features to display its beauty of technology and decoration at the same time, trying to give play to its own peculiar era features. It fully uses design features of arts and crafts to display its sense of the times. Next, as China's "design", arts and crafts should conform to production technology under modern great industry environment and use various elements in science, technology and design. Our contemporary arts and crafts is a complete design process from topic selection, conception and design to 
creating product. Arts and crafts can not be just design of formal aesthetics. As a product serving the public, it should have practical features. Arts and crafts should conform to development level of modern science and technology and use modern science and technology. Change these scientific and technical activities into conditions of development of arts and crafts. Throughout the overall development of modern "design", arts and crafts always develops with change and innovation of science, technology and production mode. Various bronze ware art wares appear with invention of bronze technology in ancient China. Various plastic arts and crafts design works appear with invention of plastic materials in contemporary China. At the same time, we should know that inventions of technology and material can assist arts and crafts in developing. Therefore, our understanding of arts and crafts can not be restricted to traditional frame. It should conform to development requirement of the times.

\section{B. Appropriateness}

Traditional art reflects space, volume and color relations. Arts and crafts is about three-dimensional and plane relation. Through its design, form, proportion, structure, color and so on, arts and crafts properly deals with overall feature, structure, form and many other contents and creates an infectious design work. At the same time, diversification and unification, comparison, proportion, rhythm, symmetry and other formal laws of art can be applied in modern arts and crafts. Of course, these laws can not be used entirely in one piece of work. Application of each formal law should be proper. For example, design of ceramic ware mainly uses formal laws of proportion, shape and so on. Some other laws are needed in dyed and woven products. A good work of arts and crafts does not depend on how many patterns are decorated, but depends on using various technologies, thus it is beautiful. Compared with ordinary art, at the same time of completing required law of art, arts and crafts adds the word of "design". It can fully use various technical principles and design laws produced in modern design to design products of arts and crafts. However, it does not mean that we should conduct accumulation of "quantity". In a deeper level, we have gotten promotion in "quality".

\section{Regionalism}

As a special art category, arts and crafts should exist alone instead of being a part of modern design's content. In the long process of history, residents on broad territory of China have creation and production of traditional arts and crafts -- since they have their own life, they would have their own creations and arts and crafts. Therefore, they naturally form and create regional peculiarity different from other areas' arts and crafts. This kind of regional feature is naturally displayed in its own craft product. Due to more rapid spreading of information, design concept and mode are spread more rapidly in a wider scope, leading to serious product similarity in modern times. Therefore, modern design emphasizes more on display of product differences. As a peculiar local product form, product of arts and crafts is the result of handing down from generation to generation in different regions from product's material to processing method of product. Result of this kind of inheriting craft is that products have obvious differences. Distinctiveness exactly caters to era requirement of modern design, especially that prosperity of cultural creative industry makes modern society pay more attention to regional culture. Regional arts and crafts product is exactly reflection of regional culture. Therefore, social development grants arts and crafts a favorable position for use in this era.

\section{Practicability}

Work of arts and crafts should be democratic. Modern design education concept in early stage originates from Bauhaus design school, whose purpose is design for the public. It is similar to our modern arts and crafts design. Our arts and crafts works should be accepted by people, and bearable and affordable in financial terms. Arts and crafts works in early stage all come from craftsmen and they are used in people's life. The biggest misunderstanding of arts and crafts is making arts and crafts a top grade artistic work which is too high to reach. As arts and crafts, one of its features of practicability, which is an important reason why this artistic category is called "arts and crafts". Departing from practicability to do art goes against original intention of arts and crafts. Modern traditional and national design is to infuse traditional culture in daily life through arts and crafts. Practicability is an important principle of popularizing arts and crafts products.

\section{UNIQUE CONTEMPORANEITY OF CHINESE ARTS AND CRAFTS}

Although Chinese traditional arts and crafts has a glorious past, through combing of history, we find that since modern times, arts and crafts changes under mighty invasion of foreign culture. Are peculiarity of Chinese arts and crafts and modernization contradictory? It is in fact a kind of modern design globalization phenomenon that peculiarity of arts and crafts draws close to modernization. Without impact of western civilization, peculiarity of Chinese arts and crafts will continue to develop. This kind of trend to draw close modernization can also exist. Mr. Li Bozhong thinks: "When arts and crafts develops in later Qing dynasty, compared with British in early modern period, conditions of various aspects of light industry development in jiangnan area is more outstanding." However, seeing from social and economic development level and technical level of that times, development potential of Chinese arts and crafts is not inferior to temporal Europe.

Formerly, we regard peculiarity of Chinese arts and crafts as "conservation", "closure", "family workshop" and some other factors, promoting forming of special features of our arts and crafts products. Due to this reason, we make our arts and crafts fall behind western countries in development after industrial revolution. In fact, after founding of China, our socalled family workshops gradually disappear and modernized development under guidance of our country becomes popular. But this kind of development can not follow steps of the times. Mr. Zhang Daoyi has deep understanding of modernization of arts and crafts and he points out: "It is covered by four contradictions. The first is quality and supply of raw material; The second is craft technology processing level; The third is quick access to economy and production information; The fourth is advancement of production and management system." 
Although these contradictions do not belong to arts and crafts, they hinder development of arts and crafts. We should seek objective reasons for development of arts and crafts outside the subject.

The so-called "peculiarity" of arts and crafts refers to design essence in Chinese traditional cultural deposits. This kind of essence is a kind of plain spirit, is a smart and diligent attitude in design and a meticulous working mode. It has to have its own features in the process of modernization. First, peculiarity of Chinese arts and crafts has to develop under the big environment of modern post-industrial era. Our understanding of arts and crafts still stays in a rather weak phase. We need to research deposits deeply, find out essence of arts and crafts and infuse it in modernized design. Second, peculiarity of arts and crafts should combine with modern high technology and high informatization new type of art. This kind of combination is not departing from features of Chinese traditional design art. It is infusing modernized technical features in traditional arts and crafts design to make it a part of peculiarity of arts and crafts. In short, peculiarity and modernization have a kind of interdependent relation, which runs through modernization all the way. This kind of peculiarity leeches on to modernized common view.

\section{CONCLUSION}

We are exploring and developing understanding of peculiarity of Chinese modern arts and crafts all the time. But it is to satisfy various human groups' production and life needs all the time. Since arts and crafts can survive in modern design wave, it shows that it has its own unique development space. Peculiarity of arts and crafts can only be significant in modernization process of society. In current China, exploration on Chinese arts and crafts is still under development. It is in an underway mode. Peculiarity of Chinese arts and crafts is a process of constant exploration. Modernization will always be broad environment of this era, requiring us to correctly deal with relation between inheriting traditional arts and crafts culture and learning foreign modern design culture in order to make peculiarity of Chinese arts and crafts always on the basis of Chinese profound traditional culture.

\section{REFERENCES}

[1] Compiled by Academic Council of Central Institute of Arts and Crafts. Decorative Art Digest. Beijing Arts and Crafts Press, 1991. 13.

[2] Chen Xiaohua. Between Craft and Art -- Modern Mileage of Chinese Art Design in the 20th Century. Chongqing University Press, 2007. 181.

[3] Li Yanzu. The Path to Decoration. Renmin University of China Press, 1993.

[4] Hang Jian. From Arts and Crafts to Art Design[J]. Decoration, 2009, (12):16-18.

[5] Li Yanzu. Contemporaneity and Regionalism of Traditional Arts and Crafts -- Re-discussion on Protection and Development of Traditional Arts and Crafts[J]. Nanjing University of the Arts Journal: Art and Design Edition, 2008, (1):5-9.

[6] Li Bozhong. Early Industrialization in Jiangnan(1550-1850). Social Sciences Academic Press, 2000. 490.

[7] Li Lixin. Chinese Design Art Historical Theory. People's Publishing House, 2011. 276 